\title{
Persistent Behavioural and Electroencephalographic Changes after Single Doses of Nitrazepam and Amylobarbitone Sodium
}

\author{
ANN MALPAS,* M.A., B.SC. ; A. J. ROWAN,† M.D. ; C. R. B. JOYCE, $\ddagger$ M.A., B.SC., PH.D. \\ D. F. SCOTT, $\mathbb{l}$ M.B., CH.B., M.R.C.P., D.P.M.
}

\begin{abstract}
Summary: In a double-blind cross-over trial the effects $\mathcal{O}$ of nitrazepam ( 5 and $10 \mathrm{mg}$.), amylobarbitone sodium (100 and $200 \mathrm{mg}$.), and placebo were compared in normal healthy young people. Though they reported a good night's sleep and adjudged themselves to be alert after all four drug treatments, behavioural tests showed their performance to be significantly impaired 13 hours after treatment with nitrazepam or amylobarbitone, and E.E.G. records showed more drowsiness and light sleep 18 hours after treatment with nitrazepam than with amylobarbitone or placebo. E.E.G. fast activity was more plentiful after drugs in either dosage than with placebo.
\end{abstract}

\section{Introduction}

Most trials of hypnotic drugs are carried out in hospitals where patients and nursing staff report on the effects of treatments. Hypnotic drugs are commonly used by patients at home, so assessment of such drugs should take into account not only the patient's subjective feelings about his sleep but also his ability, objectively assessed, to carry out skilled tasks, such as driving his car, on the day following. In the present experiment we have compared the effects of single doses of nitrazepam, amylobarbitone, or placebo in normal healthy subjects who took the treatment shortly before going to bed in their own homes and came into the laboratory for testing next day. The measures used were similar to those previously shown to be sensitive to the early effects of these treatments (Malpas and Joyce, 1969; Volavka et al., 1969).

\section{Methods}

The subjects were 10 healthy male paid volunteer medical students aged 18 to 20 years and weighing from 69 to $83 \mathrm{~kg}$. Each subject was tested five times at 14-day intervals, and on each occasion received orally nitrazepam ( 5 or $10 \mathrm{mg}$.), amylobarbitone sodium (100 or $200 \mathrm{mg}$.), or placebo double-blind according to a Latin square design. Two 5 by 5 Latin squares ensured that each treatment was preceded twice by every other treatment (Cochran and Cox, 1957). Sequences of treatments were allotted randomly to the subjects and were dispensed by one of us (C.R.B.J.), who had no contact with the subjects; the other three carried out the tests.

To reduce the likelihood of undesirable effects and other possible sources of variation, subjects were instructed not to drink any tea, coffee, alcohol, or other depressant or stimulant beverage from 8 p.m. on the experimental night until testing was completed. Each subject was seen by A.M. and given the appropriate treatment during the day before the ex-

\footnotetext{
* Research Assistant, Department of Pharmacology and Therapeutics, the London Hospital Medical College, London E.1.

+ Senior Registrar, Department of Electroencephalography, the London Hospital, London E.1. Present address: The Neurological Institute of New York (Department of Electroencephalography), Fort Wash ington Avenue and 168th Street, New York, N.Y. 10032, U.S.A.

‡ Reader in Psychopharmacology, the London Hospital Medical College, London E.1. Present address: Medical Department, Ciba A. G. 4000, Basel 7, Switzerland. Consultant, Department of Electroencephalography, the London Hos-
pital, London E.1.
}

periment. He was instructed to take the pills at 11 p.m. the same night and then to go to bed. On waking in the morning he filled in a questionary about the night's sleep and came into ine laboratory a few hours later for testing (Table I).

TABLE I.-Experimental Schedule for Each Subject Day 1.-11 p.m.: First treatment, followed by sleep at home

Day 2.-On waking: Sleep questionnaire. 12-12.30 p.m.: Subjective and behaviour:11 tests (13 hours after treatment). 4-4.30 p.m.: Subjective and behavioural tes (17 hours after treatment). 5-6 p.m.: E.E.G. (18 hours after treatment)

Day 15.-11 p.m.: Second treatment, etc.

Sleep Questionnaire.-This was derived from that used by Morgan, Scott, and Joyce (1970), and contained questions relating to the quality, duration, rapidity of onset, and subjective depth of sleep and to condition on awakening. The subject rated his answer to each question on a 5-point scale such that the middle category represented the "as usual" condition and the highest score indicated maximal hypnotic effect.

Subjective Mood Scale.-The subject was instructed to work quickly through the 81 -item list of adjectives used by Reynolds, Joyce, Swift, Tooley, and Weatherall (1965), rating each one, as it related to him at the moment, on a 3-point scale-“true," "don't know," "false." In scoring this test, clusters of adjectives relating to tension, good mood, and drowsiness were extracted from the list and the number of times the adjectives in each cluster were checked as true, don't know, or false was totalled for each category (Reynolds et al., 1965).

Card Sorting.-The time taken to sort 32 playing-cards into two, four, or eight piles was measured in seconds (Crossman, 1953). When all the cards in a pack were identical the "motor" time taken to deal out the cards into two, four, or eight piles was evaluated. When the packs contained two, four, or eight different types of card the total time taken to sort the cards into the categories was measured. By subtracting the appropriate motor time from the total time an estimate was obtained of the "decision" time taken to choose between two, four, or eight responses.

Electroencephalogram (E.E.G.).- The subject lay on a comfortable couch in a quiet darkened room during the 30-minute recording, the same Schonander 16-channel machine being used each time. "Stick-on" electrodes were placed by one of three E.E.G. recordists according to the 10/20 system, and recording montages included parasagittal, transverse, and temporal arrangements. The first 20 minutes of each record was divided into 10-second epochs. Each epoch was independently rated blind by two of us (D.F.S. and A.J.R.) for the occurrence of electrical phenomena associated with drowsiness and light sleep. The method of rating was based on that used by Prior and Deacon (1969), a numerical value from 0 to 3 being given to each epoch, the rating scale being as follows:

0 -Any epoch showing alpha activity for greater than $50 \%$ of the time.

1-Any epoch showing alpha activity for less than $50 \%$ of the time but containing no paroxysmal features of sleep.

2-Any epoch showing one definite paroxysmal feature of 
sleep-that is, vertex sharp waves, sleep spindles at 12-14 cycles per second, lambdoid waves (at least 15 microvolts), K-complexes.

3-Any epoch showing continuous delta activity for more than $50 \%$ of the time.

The figures so obtained were summed to give a total soore for each record. An interrater reliability study indicated a $95 \%$ concordance of ratings. The individual ratings were compared at the end of the study and disagreements were resolved by a review of the epochs in question. Fast activity (18-24 c.p.s.) was separately rated in all records and assigned a value of 1,2 , or 3 according to the amount present. The time to the onset of sleep was measured from the beginning of the artifact-free recording to the first occurrence of two successive epoch ratings of 2 points.

Analysis.-The behavioural test results were submitted to parametric analysis of variance. Differences between the effects of treatments on the subjective assessments and E.E.G. ratings were analysed by Friedman's two-way analysis of variance.

\section{Results}

Sleep Questionnaire.-Subjects did not report hangover effects (drowsiness or difficulty in waking in the morning) after any treatment, and these did not differ in their effects on the subjective onset of sleep. They did rate themselves as having had a better and longer night's sleep after high doses of both drugs than after placebo $(P<0.05)$ or after the lower drug doses.

Subjective Mood Rating.-There were no differences between treatments with respect to feelings of "tension" or "good mood" at either 13 or 17 hours. Subjects rated themselves as "alert" more often after drug than after placebo $(P<0.05)$ at 13 hours, but this effect was no longer detectable at 17 hours.

Card Sorting.-Motor performance after placebo was little affected by the number of piles into which the cards were sorted (Table II). Performance after both doses of nitrazepam was slower than after placebo at 13 hours $(P<0.05)$, but at 17 hours the same trend, though still apparent, did not reach the $5 \%$ level of significance. Neither dose of amylobarbitone

TABLE II.-Time Taken to Sort 32 Cards 13 Hours after Treatment (Mean Time in Seconds \pm Standard Error)

\begin{tabular}{|c|c|c|c|c|c|}
\hline & \multirow{2}{*}{ Placebo } & \multicolumn{2}{|c|}{ Nitrazepam } & \multicolumn{2}{|c|}{ Amylobarbitone } \\
\hline & & $5 \mathrm{mg}$. & $10 \mathrm{mg}$. & $100 \mathrm{mg}$. & $200 \mathrm{mg}$. \\
\hline \multicolumn{6}{|c|}{ Motor Time } \\
\hline $\begin{array}{l}2 \\
4 \\
8\end{array}$ & $\begin{array}{l}15 \cdot 44 \pm 0.84 \\
15 \cdot 46 \pm 0.80 \\
15.61 \pm 0.79\end{array}$ & $\mid \begin{array}{l}15.71 \pm 0.80 \\
15.78 \pm 0.80 \\
16.06 \pm 0.80\end{array}$ & \begin{tabular}{|l|l}
$16 \cdot 25$ & 0.82 \\
$16 \cdot 28$ & 0.82 \\
16.79 & 0.89
\end{tabular} & \begin{tabular}{|l|l|}
15.61 & 0.81 \\
15.67 & 0.79 \\
15.90 & 0.81
\end{tabular} & $\begin{array}{l}15.36+0.82 \\
15.63+0.81 \\
15.64 \pm 0.81\end{array}$ \\
\hline \multicolumn{6}{|c|}{ Decision Time } \\
\hline $\begin{array}{c}2 \\
4 \\
8\end{array}$ & $\begin{array}{l}14 \cdot 75 \pm 2.43 \\
19.94 \pm 3.14 \\
24.86+3 \cdot 12\end{array}$ & $\mid \begin{array}{l}14.97 \pm 2 \cdot 12 \\
20.17 \pm 3.17 \\
25.07 \pm 4.31\end{array}$ & $\mid \begin{array}{r}15.75+2.27 \\
20.44+3.45 \\
26.70+6.05\end{array}$ & $\mid \begin{array}{l}14 \cdot 09+2 \cdot 60 \\
19 \cdot 70+3 \cdot 75 \\
25 \cdot 52 \pm 5 \cdot 13\end{array}$ & $\begin{array}{l}15.49 \pm 2.09 \\
20.91 \pm 3.96 \\
26.46+4.89\end{array}$ \\
\hline
\end{tabular}

slowed performance significantly in comparison with placebo at either time of testing. Decision time was significantly slowed 13 hours after treatment with $10 \mathrm{mg}$. of nitrazepam and $200 \mathrm{mg}$. of amylobarbitone compared with placebo (Table II), but $5 \mathrm{mg}$. of nitrazepam had little effect on speed of decision-making, and $100 \mathrm{mg}$. of amylobarbitone resulted in performance significantly slower than placebo for sorting into eight categories only. At 17 hours some slowing of performance after drug treatment was still apparent, but no difference was statistically significant.

E.E.G. Studies. - The mean total sleep ratings for each treatment are shown in Table III. The scores were higher
TABLE III.-E.E.G. Changes 18 Hours After Treatment

\begin{tabular}{|c|c|c|}
\hline & $\begin{array}{c}\text { E.E.G. Sleep Rating } \\
\text { (Total Score over } 20 \text { Minutes) }\end{array}$ & $\begin{array}{c}\text { Time to Onset of Sleep } \\
\text { (Minutes) }\end{array}$ \\
\hline $\begin{array}{l}\text { Placebo... } \\
5 \text { mg. nitrazepam } \\
10 \text { mg. nitrazepam } \\
100 \text { mg. amylobarbitone } \\
200 \text { mg. amylobarbitone }\end{array}$ & $\begin{array}{l}132 \cdot 9 \\
160 \cdot 2 \\
186 \cdot 2 * \\
149 \cdot 4 \\
150 \cdot 9\end{array}$ & $\begin{array}{l}10 \cdot 1 \\
6 \cdot 5^{*} \\
5 \cdot 3^{*} \\
8 \cdot 5 \\
7 \cdot 8\end{array}$ \\
\hline
\end{tabular}

*Differs from placebo value $P<0.05$.

after each drug treatment than after placebo, but only the results for $10 \mathrm{mg}$. of nitrazepam differed significantly. The onset of sleep was faster with all drug treatments than with placebo. These differences were significant only for 5 and 10 mg. of nitrazepam. Ratings of fast activity were higher for all drug treatments.

\section{Discussion}

The results show that, with measures known to be sensitive to the effects of hypnotic drugs (Malpas and Joyce, 1969), some slowing of performance is detectable for at least 12 hours after a normal healthy subject has taken a hypnotic dose of either amylobarbitone sodium or nitrazepam shortly before going to bed. Similar effects on behavioural measures following treatment with barbiturates have previously been shown for quinalbarbitone (Kornetsky, Vates, and Kessler, 1959) and for pentobarbitone (Goodnow, Beecher, Brazier, Mosteller, and Tagiuri, 1951), but reports of persistent behavioural effects following nitrazepam have been negative (Ditt, 1964) except with large doses (Harrer, 1965).

Subjective feelings of drowsiness were not reported on the day after any drug treatment in the present experiment. Such effects, however, have been reported for hospital patients after amylobarbitone and less frequently after nitrazepam (Wyss and Mäder, 1965; Davies and Levine, 1967; Haider, 1968). In a study similar in some respects to the present one using normal subjects sleeping at home, Morgan et al. (1970) described pronounced subjective hangover effects after $10 \mathrm{mg}$. of nitrazepam. The lack of such reports in the present experiment may be because the subjects were not asked to rate their feelings until 12 noon the next day or because they were much younger. At the time when they rated themselves as being more alert after drug than after placebo their performance on behavioural tasks showed some slowing.

In the late afternoon, at a time when psychomotor performance and subjective assessments were no longer significantly affected by treatment with drugs, the E.E.G. was a sensitive indicator of persistent drug effect. E.E.G. changes indicative of increased drowsiness which were seen after drug treatment have also been used by Doenicke, Kugler, Schellenberger, and Gürtner (1966) to show the prolonged effects of intravenous anaesthetics. Another effect-namely, fast activity-was present in the E.E.G. record 18 hours after the single doses of both nitrazepam and amylobarbitone. This effect is normally associated with barbiturates, but its presence after nitrazepam is in agreement with the results of Oswald and Priest (1965), who reported excess fast activity detectable for up to three days after nitrazepam treatment of $15 \mathrm{mg}$. per night for 14 consecutive nights had ended.

Nitrazepam, which has been shown to be as effective as butobarbitone (Matthew, Proudfoot, Aitken, Raeburn, and Wright, 1969) and amylobarbitone (Davies and Levine, 1967) as a sleep-inducing agent in hospital patients, is also an effective hypnotic in subjects sleeping at home (Morgan et al., 1970). The effects of nitrazepam, however, are at least as prolonged as those of amylobarbitone, and certain kinds of performance may be significantly slowed the next day even though the subject may be unaware of this. The present 
laboratory study suggests therefore, that further experimental and clinical evaluation of hypnotics in common use, whether barbiturates or not, is urgently required.

We are grateful to our subjects; to Roche (Products) Limited, who kindly provided, through Dr. M. Duffus, the placebo and active treatments as well as generous financial support to one of us (A.M.); and to Miss S. Virdian and D. Navsa for help with the E.E.G. recordings.

\section{REFERENCES}

Cochran, W. G., and Cox, G. M. (1957). Experimental Designs. London, Chapman and Hall.

Crossman, E. R. F. W. (1953). Quarterly fournal of Experimental Psychology, 5, 41 .

Davies, C., and Levine, S. (1967). British Fournal of Psychiatry, 113, 1005 .
Ditt, J. (1964). Congress of the German Society of Forensic and Social Medicine, Zurich, 17 October.

Doenicke, A., Kugler, J., Schellenberger, A., and Gürtner, T. (1966). British fournal of Anaesthesia, 38, 580 .

Goodnow, R. E., Beecher, H. K., Brazier, M. A. B., Mosteller, F., and Tagiuri, R. (1951). fournal of Pharmacology and Experimental Therapeutics, 102, 55

Haider, I. (1968). British fournal of Psychiatry, 114, 337.

Harrer, G. (1965). Progress in Brain Research, 18, 228.

Kornetsky, C., Vates, T. S., and Kessler, E. K. (1959). Fournal of Pharmacology and Experimental Therapeutics, 127, 51 .

Malpas, A., and Joyce, C. R. B. (1969). Psychopharmacologia, 14, 167.

Matthew, H., Proudfoot, A. T., Aitken, R. C. B., Raeburn, J. A., and Wright, N. (1969). British Medical fournal, 3, 23

Morgan, H., Scott, D. F., and Joyce, C. R. B. (1970). British fournal of Psychiatry. In press.

Oswald, I., and Priest, R. G. (1965). British Medical fournal, 2, 1093.

Prior, P. F., and Deacon, P. A. (1969). Electroencephalography and Clinical Neurophysiology, 27, 422.

Reynolds, E., Joyce, C. R. B., Swift, J. I., Tooley, P. H., and Weatherall, M. (1965). British fournal of Psychiatry, 111, 84.

Volavka, J. V., et al. (1969). Psychopharmacologia 14, 178 .

Wyss, S and Mäder, A (1965) Schweizerische medizinische Wochenschrift, 95, 338

\title{
Long-term and Short-term Effects of Oral Prethcamide in Chronic Ventilatory Failure
}

\author{
R. A. L. BREWIS, ${ }^{*}$ M.D., ; M.R.C.P. N. G. HODGES, $\dagger$ M.B., B.CH., M.R.C.P.
}

Sum ummary: The effect of oral prethcamide (Micoren) (a mixture of two related amides of crotonyl $\mathbf{N}^{\prime}$ butyric acid) was compared with a placebo preparation in 13 patients with established chronic ventilatory failure. Part I of the study comprised a double-blind single crossover trial with an initial assessment and two further assessments at the end of each period of one month. Prethcamide was taken in 200-mg. doses four times daily. No subjective or objective changes were noted, and in particular the resting $\mathrm{PCO}_{2}$ showed no change.

Part II of the study comprised a double-blind single cross-over trial of the short-term effect of prethcamide compared with placebo in 12 patients in chronic ventilatory failure. Frequent estimations of mixed venous PCO: were made with a rebreathing technique for four and a half hours after ingestion of prethcamide or placebo preparation.

Following prethcamide a fall in PCO.2 level to a minimum value at 30 minutes of $93 \%$ of control values and persisting for about three hours was noted for the group as a whole. The fall represents a lowering by about $4 \mathrm{~mm}$. $\mathrm{Hg}$ of the mixed venous $\mathrm{PCO}_{2}$.

It is concluded that, though in patients with chronic ventilatory failure prethcamide may reduce the PCO: in the short term, there is no subjective benefit or observable objective change following repeated administrations over a period of one month.

\section{Introduction}

Patients with obstructive airways disease who develop chronic ventilatory failure commonly have a less severe degree of air-

* Lecturer in Medicine, University of Manchester. At present Senio Lecturer in Medicine, Royal Victoria Infirmary, Newcastle upon Tyne NE1 4LP.

+ Research Fellow, United Manchester Hospitals. At present Registrar in Medicine, Southampton General Hospital, Southampton. ways obstruction than some other patients who are, nevertheless able to maintain a normal arterial $\mathrm{PcO}_{2}$. While there may be differences of lung morphology in these two groups, there is strong evidence that some patients with chronic hypoventilation have a defective central drive to breathe, and voluntary overbreathing in these individuals results in a lowering of the arterial $\mathrm{PCO}_{2}$ and an increase in $\mathrm{Po}_{2}$. In these patients stimulation of ventilation might prove beneficial. Respiratory stimulants such as nikethamide have found some place in the management of acute respiratory failure accompanying acute exacerbations of chronic obstructive airways disease (Lancet, 1963). Prethcamide (Micoren), a mixture of two related amides of crotonyl $\mathrm{N}^{\prime}$ butyric acid, has been shown to stimulate respiration in the short term (Domenet and Kennedy, 1967) and has been used in the acute situation, but no controlled trial of the long-term use of this drug, orally, in patients with established chronic ventilatory failure has been reported to date.

\section{Patients and Methods}

\section{Part I. Long Term}

Sixteen patients with chronic ventilatory failure attending the respiratory clinic at Manchester Royal Infirmary were admitted to the trial. In every case the three previous estimations of the arterial $\mathrm{PCO}:$ were in excess of $44 \mathrm{~mm}$. $\mathrm{Hg}$ and extended over a period of at least three months before the beginning of the trial. The study took the form of a doubleblind comparison of prethcamide and placebo, each administered for four weeks. All patients had an initial assessment, and a further assessment at the end of each period. Prethcamide was prescribed in the form of capsules, each containing $200 \mathrm{mg}$., and a dose of $400 \mathrm{mg}$. was taken four times daily. The patients were provided with typewritten information about the trial and specifically urged to continue taking the capsules up to and including the morning of the next assessment. The placebo preparation was identical in appearance. 